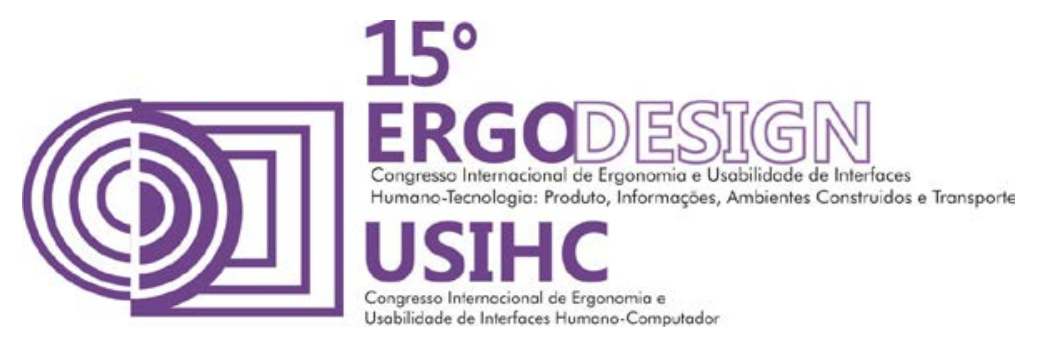

\title{
EMBALAGEM DE FRUTAS MUSTACHE BOX — FABRICAÇÃO DIGITAL E MODELAGEM PARAMÉTRICA APLICADAS AO DESIGN DE PRODUTO
}

\author{
BRUNO, Fernando Batista (1) \\ RAGUZE, Tiago (2) \\ SÁ, Adreson Vilson Vita de ${ }^{(3)}$ \\ (1) UFRGS, Doutorado em andamento em Design \\ e-mail: fernando.bruno@ufrgs.br \\ (2) UFRGS, Mestrado em andamento em Design \\ e-mail: tiagoraguzze@gmail.com \\ (3) UFRGS, Mestrado em andamento em Design \\ e-mail: $\underline{\text { adreson@gmail.com }}$
}

\begin{abstract}
RESUMO
Este trabalho apresenta o desenvolvimento de um produto baseado nos conceitos de modelagem paramétrica e fabricação digital. Tais conceitos trazem consigo a possibilidade de otimizar os recursos investidos no processo de design, aumentando a produtividade, além de agilizar as fases de prototipagem e de ajuste do projeto. A partir de um problema proposto: diminuir as grandes perdas causadas pelo desperdício de alimentos na fase de pós-produção, o produto desenvolvido ao longo desta pesquisa é uma embalagem para o transporte de frutas. Para a geração de ideias foi utilizado o jogo Creative Sketch, desenvolvido por Cardozo (2012), e a modelagem paramétrica, realizada no software Rhinoceros 3D com o plugin Grasshopper.
\end{abstract}

\begin{abstract}
This paper presents the development of a product, based on parametric modeling and digital fabrication. Whose concepts allow the possibility to optimize the resources invested in the design process, increasing productivity, and streamline the stages of prototyping and design setting. From a proposed problem: reducing the heavy losses caused by food waste in the post-harvest stage, the product developed along this research is a package for small-scale fruit. In generating ideas, the "Creative Sketch" game was used and parametric modeling drawn up in Rhinoceros 3D software with Grasshopper plugin.
\end{abstract}

\section{INTRODUÇÃO}

O desperdício de alimentos é um problema global. De acordo com dados da ONU, um terço da produção mundial de alimentos é desperdiçada, causando um prejuízo de aproximadamente 750 bilhões de dólares por ano. Observou-se que a maior parte das perdas acontece nas etapas de pós-produção, como o transporte de alimentos (ONU BR, 2013). 


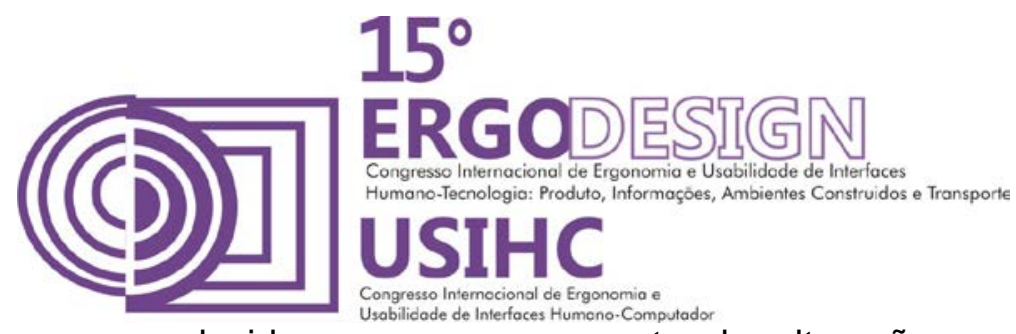

As perdas podem ser reduzidas com uma proposta de alteração na forma como os alimentos são transportados. O desenvolvimento de novos tipos de embalagem, que ofereçam maior proteção à carga, otimizando a utilização de espaço, pode tornar mais eficiente o transporte, beneficiando produtores e consumidores.

Com o objetivo de otimizar o processo de design de um novo tipo de embalagem, assim como potencializar a reutilização do mesmo projeto para diferentes tipos de alimentos e agilizar as fases de geração de alternativas e de prototipagem, conceitos como modelagem paramétrica e fabricação digital podem ser aplicados desde o início do processo até sua finalização.

A modelagem paramétrica substitui as características de um objeto, como suas dimensões, por relações entre os elementos que o compõem, criando parâmetros (variáveis independentes) e restrições (variáveis dependentes). A variação nos valores dos parâmetros altera a forma do objeto.

A fabricação digital, de uma forma geral, se refere à fabricação em um processo controlado por computador. No contexto deste trabalho, este termo está ligado à ideia que levou o MIT (Massachusetts Institute of Technology) a desenvolver e difundir os FabLabs: pequenas oficinas de fabricação dotadas de fresadora, máquina de corte, impressora e digitalizador tridimensional, controlados por um computador, onde um indivíduo pode realizar o processo desde a concepção até a produção (GERSHENFELD, 2012).

O objetivo deste trabalho é, a partir da modelagem paramétrica, desenvolver e produzir o protótipo de uma embalagem para transporte de alimentos, em um ambiente de fabricação digital: o Laboratório de Design e Fabricação Digital do Núcleo de Pesquisa Virtual Design da Universidade Federal do Rio Grande do Sul (ViD-UFRGS), que possui os equipamentos necessários para este processo.

\title{
2. DESENVOLVIMENTO
}

A partir da problematização, foi proposto um briefing para a geração de alternativas de uma embalagem para o transporte de alimentos com o propósito de reduzir o desperdício.

Com base no briefing proposto, foi escolhido as embalagens de frutas para o desenvolvimento do produto. Este é um nicho interessante para ser explorado, pois trata-se de um alimento com certa fragilidade e o seu transporte apresenta problemas que podem ser resolvidos através do desenvolvimento de uma embalagem mais eficiente.

\subsection{Embalagem de frutas}

A Associação Brasileira de Embalagem (ABRE) define:

\begin{abstract}
A embalagem é um recipiente ou envoltura que armazena produtos temporariamente, individualmente ou agrupando unidades, tendo como principal função protegê-lo e estender o seu prazo de vida (shelf life), viabilizando sua distribuição, identificação e consumo.
\end{abstract}

(ABRE, 2014)

Bordin (2000, p. 33) simplifica as principais funções da embalagem: conter, proteger e vender um determinado produto.

Segundo Bordin (2000), as maiores adversidades encontradas no processo de distribuição de produtos agrícolas são:

- Manuseio severo durante as operações de carga e descarga; 


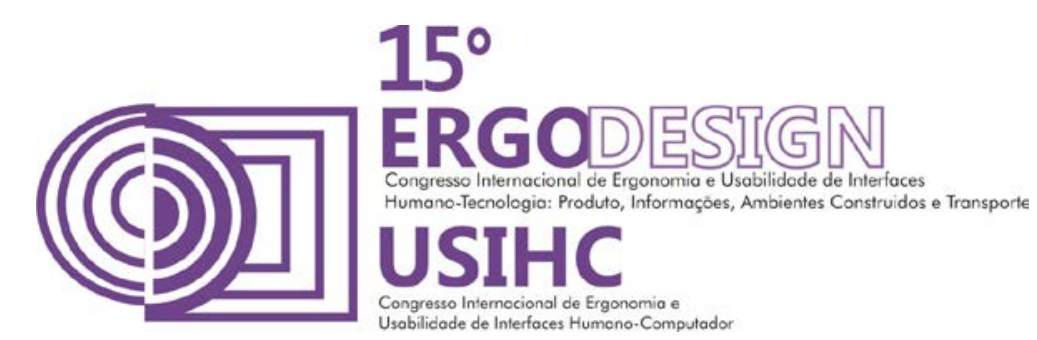

- Compressão das caixas colocadas sobre as camadas inferiores;

- Impactos e vibrações durante o transporte;

- Perda de umidade para o ambiente;

- Presença de etileno;

- Odores de outros produtos ou resíduos.

Os tipos de materiais mais empregados em embalagens para o acondicionamento de frutas e hortaliças, segundo Calbo e Luengo (2006), são madeira, papelão, plástico, juta e nylon, sendo os sacos de juta e nylon utilizado no transporte de batatas e cebolas, respectivamente. As caixas de madeira, papelão ou plástico são as embalagens mais utilizadas para a distribuição de frutas.

Conforme Bordin (2000), as caixas elaboradas com cada um destes materiais apresentam características particulares:

- Madeira: o tipo mais utilizado no Brasil, geralmente confeccionada com madeira de reflorestamento como pinus e eucalipto. Estas caixas apresentam elevada resistência vertical e baixo custo, porém sua superfície é áspera e pode causar danos aos produtos. Podem ser reutilizadas, porém, pela dificuldade de higienização, podem acumular resíduos ou apresentar o surgimento de fungos, causando contaminação dos produtos (BORDIN, 2000). Existem vários modelos de caixa de madeira como o engradado (Figura 1A), o modelo M (Figura 1B), o modelo K (Figura 1C) e o torito (Figura 1D);

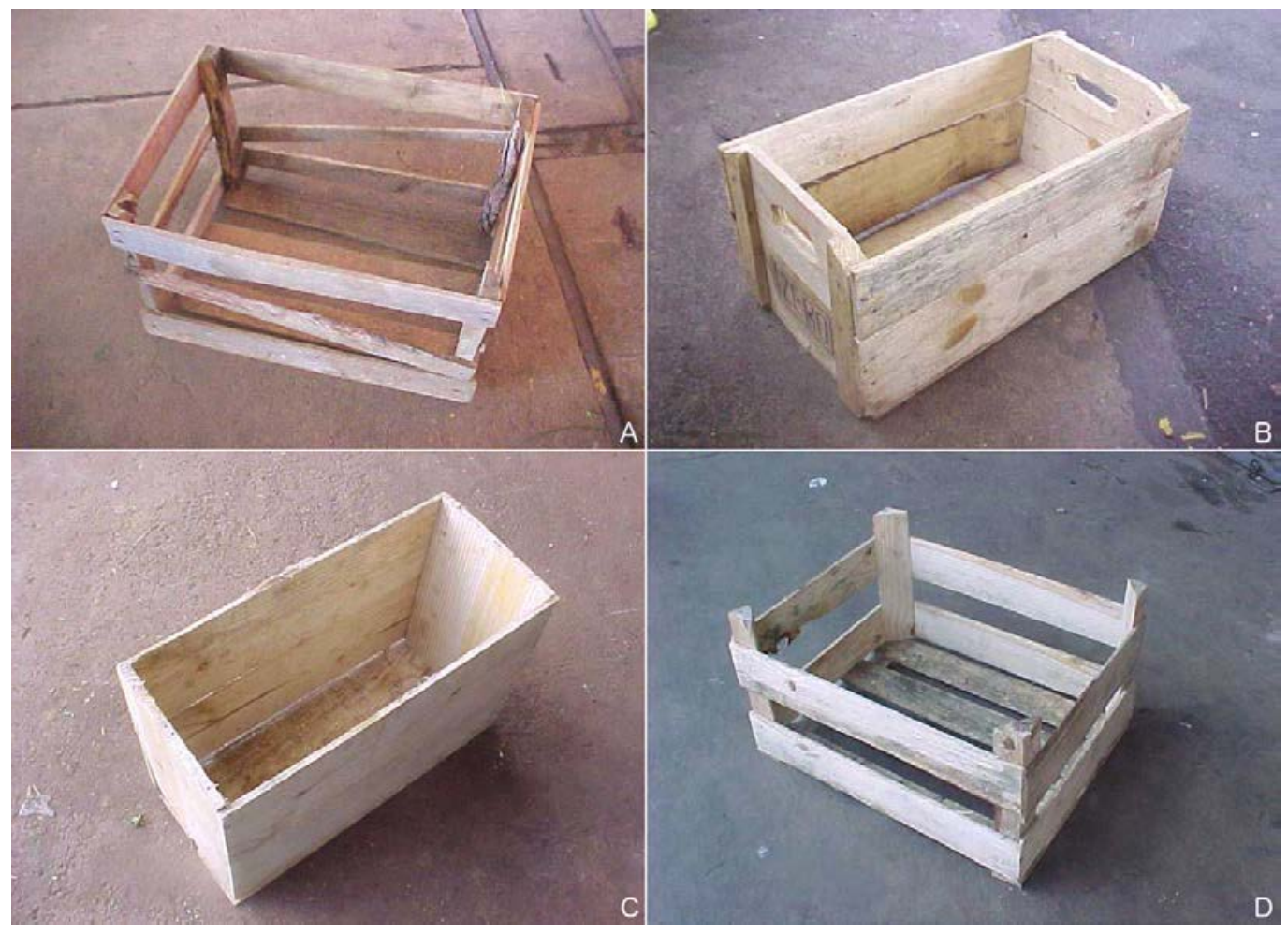

Figura 1 - embalagens de madeira.

Fonte: Hortibrasil, 2009.

- Papelão ondulado (Figura 2A): apresentam boa resistência vertical e sua superfície é lisa, o que minimiza danos devidos a impactos e abrasão. Porém, por apresentar 


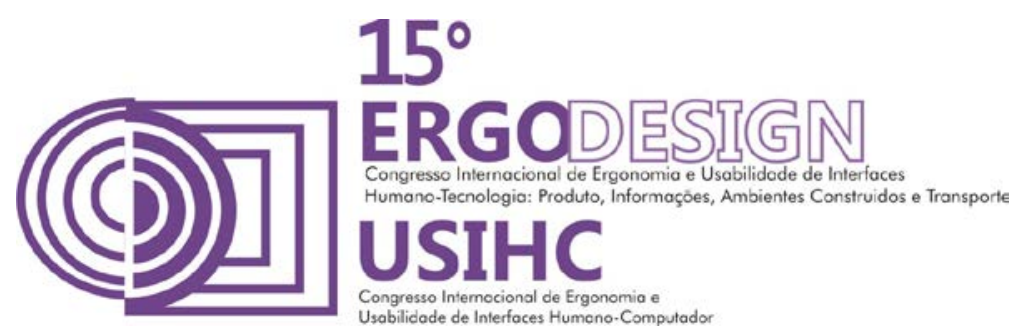

maior flexibilidade, permite maior mobilidade do conteúdo, o que pode causar choques entre os produtos embalados. As caixas confeccionadas em papelão apresentam um custo maior que as de madeira e apresentam baixa resistência a condições de umidade elevada são descartáveis, minimiza a ocorrência de danos (BORDIN, 2000);

- Plástico (Figura 2B): apresentam alta resistência e durabilidade, podendo ser higienizadas para reutilização, evitando contaminação. Estas caixas são fabricadas por injeção e seu custo é elevado (BORDIN, 2000).
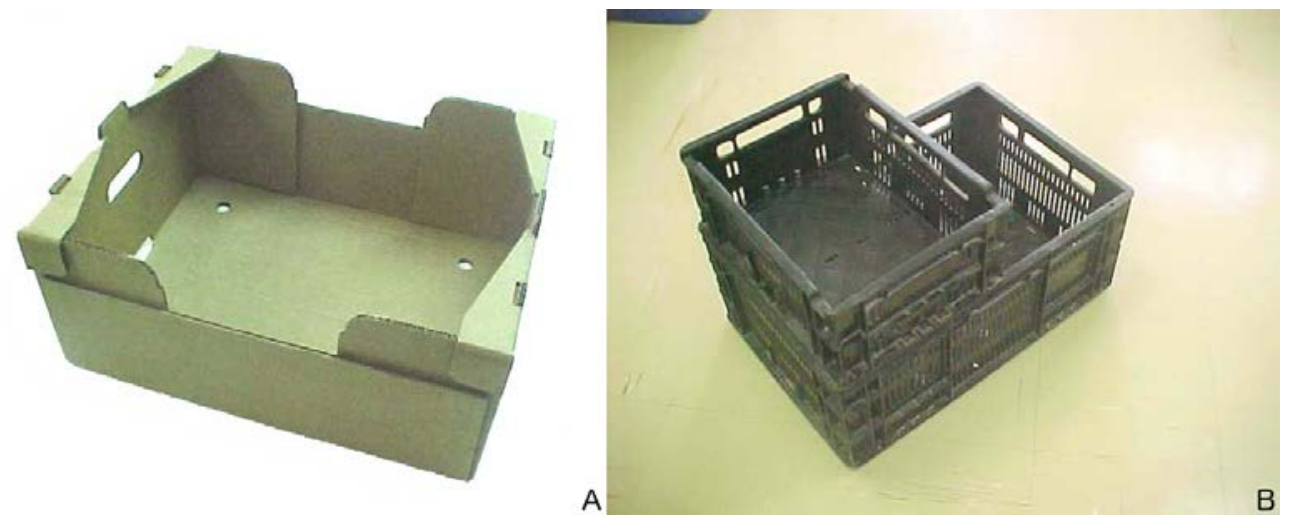

Figura 2 - embalagens de papelão (A) e de plástico (B).

Fonte: Hortibrasil, 2009.

\subsection{Geração de Ideias}

Para a geração de ideias, foi utilizado o Creative Sketch desenvolvido por Cardozo (2012). O jogo consiste basicamente em uma espécie de competição no qual equipes geram inúmeras ideias de acordo com cinco etapas. Na primeira, cria-se a maior quantidade possível de ideias a partir do problema proposto.

Na segunda etapa, cada equipe recebe uma palavra fora do contexto do problema proposto e deve gerar ideias a partir dela. Na terceira etapa, cada equipe deve criar ideias a partir de conceitos de design previamente sorteados entre as equipes. Na quarta etapa, as equipes devem criticar as ideias dos outros grupos a fim de prevalecer a sua ideia. $O$ final do jogo resultou em cinco ideias que se tornaram os conceitos principais para o desenvolvimento do produto proposto. Os conceitos foram: flexibilidade, modularidade, tubos seletores, canaletas/telas e fechamento a vácuo (Figura 3). 


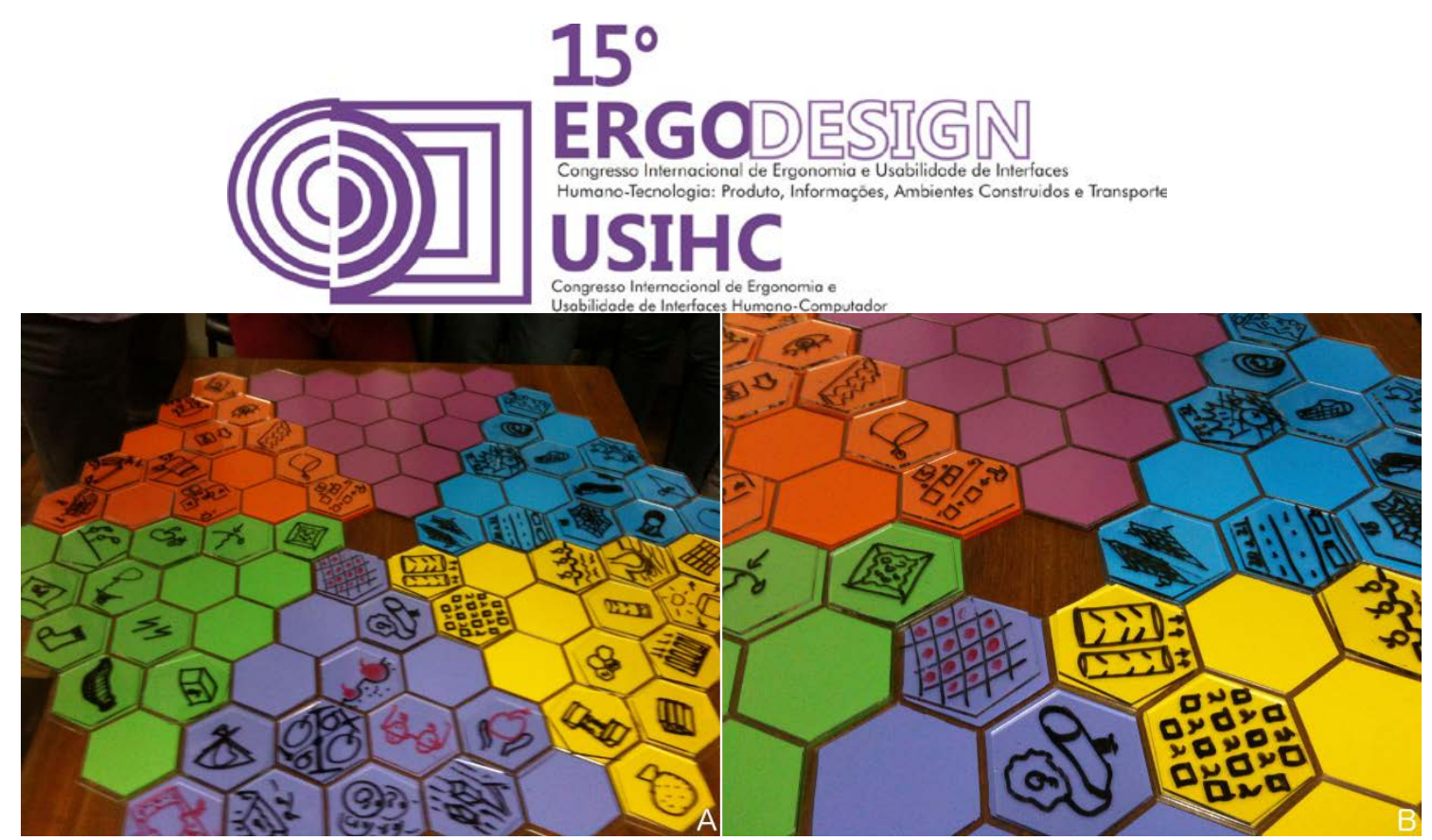

Figura 3 - geração de alternativas com o jogo Creative Sketch.

Elaborado pelos autores, com base na pesquisa realizada.

\subsection{Definição do Escopo}

A partir das informações pesquisadas, optou-se por segmentar o produto embalagem. Os pequenos comerciantes (Figura 4) que são abastecidos pelos grandes centros de distribuição, apresentam uma preocupação maior com o desperdício. Compras em pequenas quantidades, que não podem estragar durante o transporte. Neste contexto que foram desenvolvidos os esboços de uma nova embalagem. Um produto para o transporte simples, que acomodasse bem as frutas, e que ao mesmo tempo já oferece a possibilidade de utilizar como gôndola no ponto de venda.

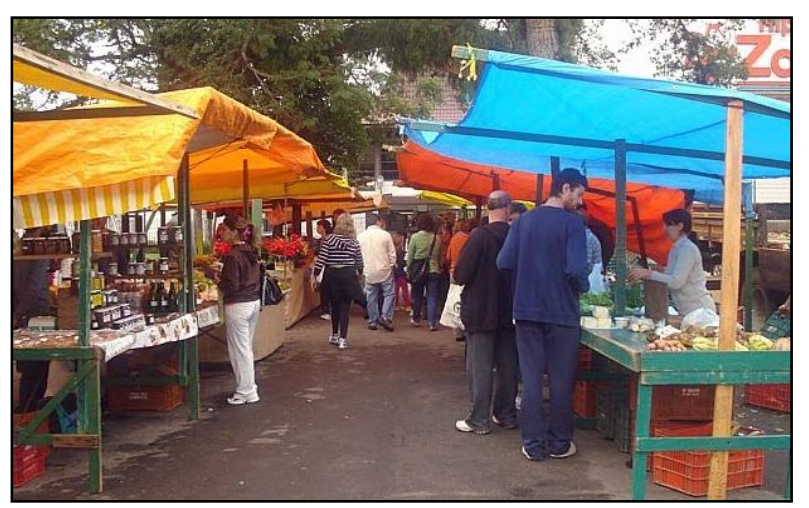

Figura 4 - feira popular em Porto Alegre.

Elaborado pelos autores, com base na pesquisa realizada

\subsection{Geração de alternativas}

Antes de projetar a primeira versão do produto, foram elaborados esboços, apresentados na Figura 5, para buscar um esquema que pudesse atender os critérios (ou restrições) definidos anteriormente através do jogo Creative Sketch. 


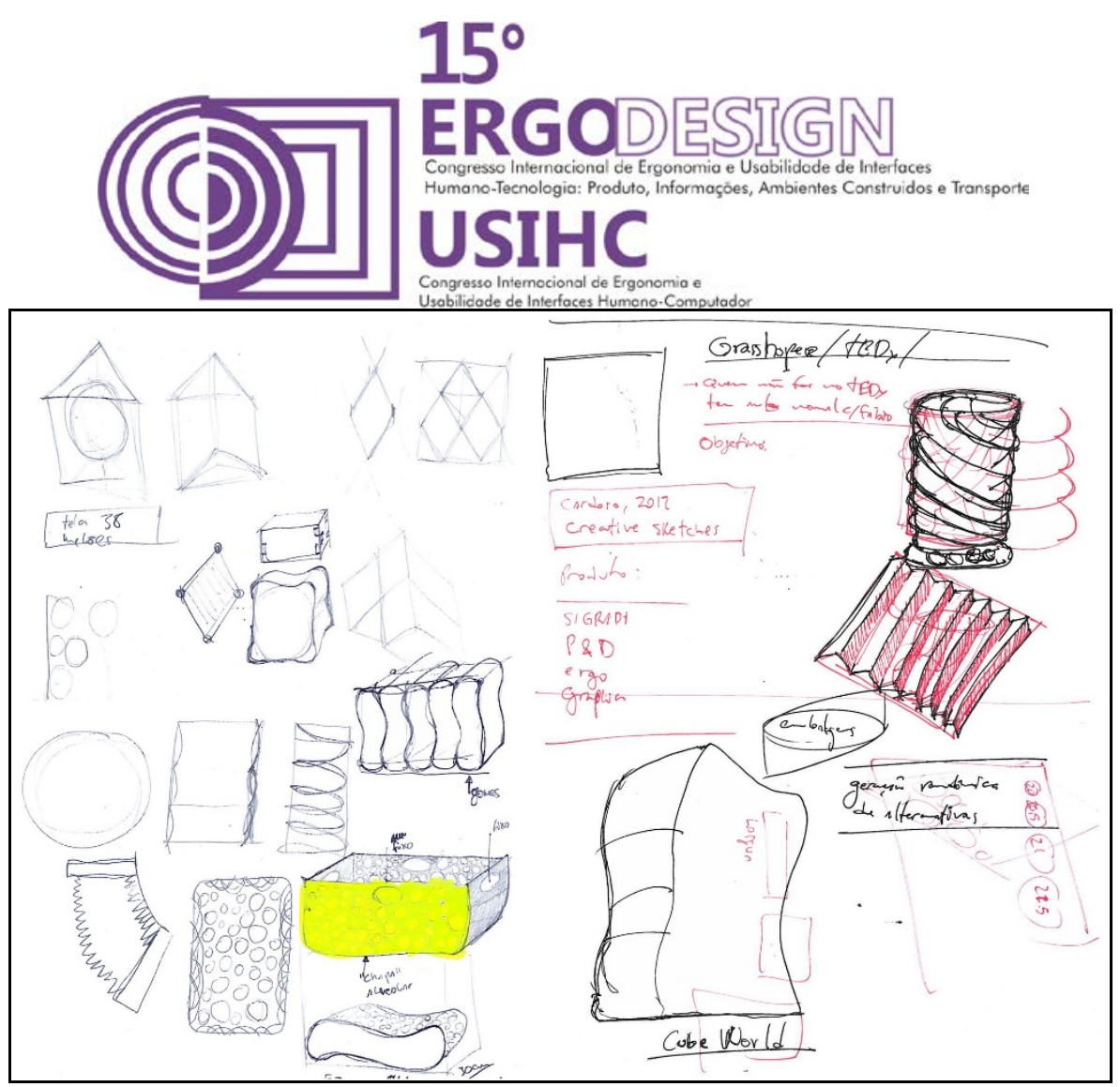

Figura 5 - esboços - busca de alternativas.

Elaborado pelos autores, com base na pesquisa realizada.

A Figura 6 mostra o esboço que selecionado, com a ideia de uma bandeja onde as frutas ficam acopladas nos encaixes. Os nichos devem ser ajustados para cada tipo de produto a ser transportado. A proposta também busca servir de expositor para venda ao consumidor final.

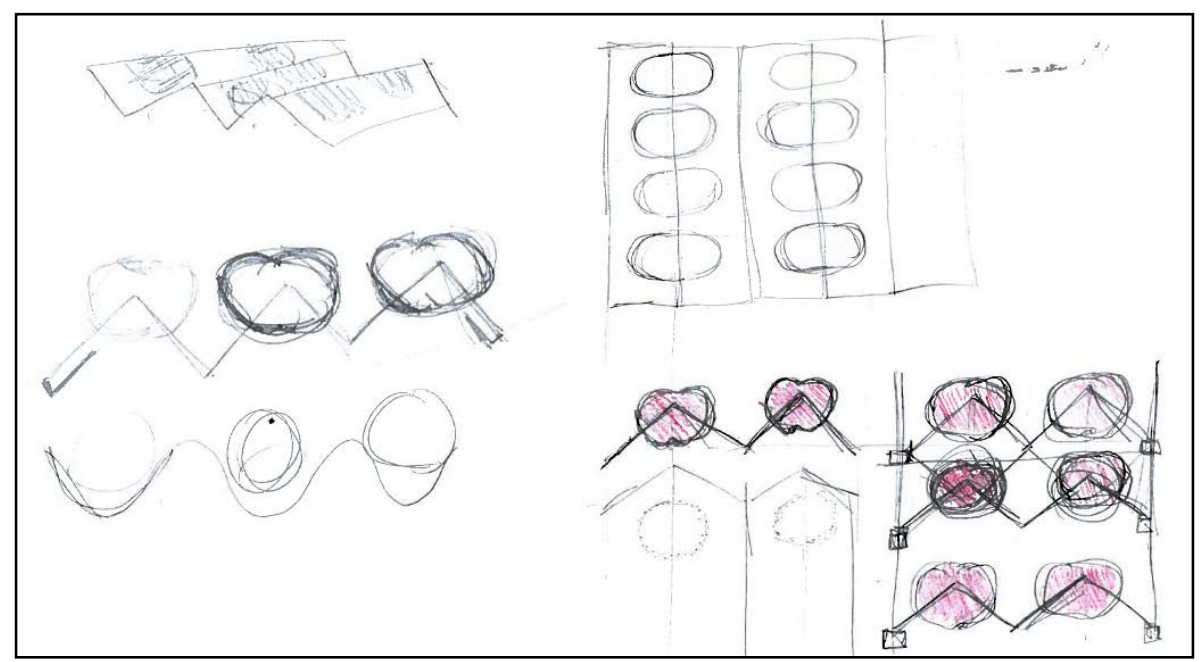

Figura 6 - esboços - busca de alternativas.

Elaborado pelos autores, com base na pesquisa realizada. 


\subsection{Modelagem Paramétrica}

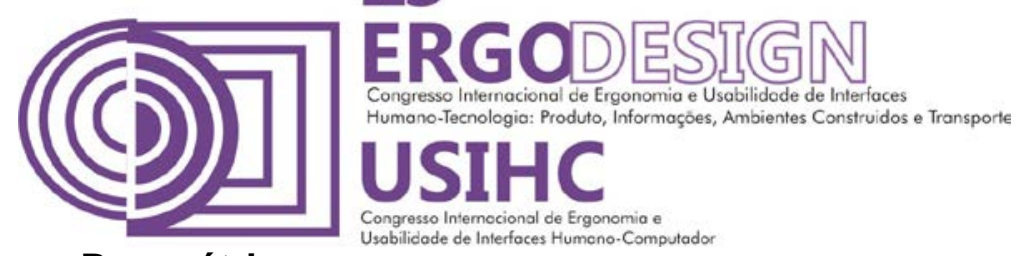

A modelagem paramétrica implica na utilização de parâmetros na definição de relações entre os elementos de um objeto (MONEDERO, 2000). Segundo Gross (1990), em um sistema paramétrico as características de um modelo são substituídas por variáveis que, conforme têm seus valores alterados, modificam a forma do modelo.

Gross ainda afirma que, apesar de representar um grande avanço na forma como os objetos são modelados, a parametrização traz consigo a dificuldade na determinação de quais propriedades do modelo devem ser substituídas por variáveis independentes (parâmetros) e quais serão as variáveis dependentes (restrições) (GROSS, 1990). O designer, segundo Barrios Hernandez (2006, p. 310), deve prever que tipos de transformação o modelo será capaz de suportar e decidir quais relações serão parametrizadas para este objetivo. A dificuldade está na "natureza imprevisível do processo de design" (BARRIOS HERNANDEZ, 2006, p. 310).

O modelo paramétrico serve de base para o design paramétrico, que é o processo que substitui singularidades por multiplicidades e proporciona maior flexibilidade ao projeto (BARRIOS HERNANDEZ, 2006).

Um estudo realizado na área de Engenharia Civil aponta que a adoção de ferramentas paramétricas pode representar um incremento na produtividade, com um aumento entre $21 \%$ e $61 \%$ na produção de desenhos e redução do tempo total dedicado ao projeto entre $15 \%$ e $41 \%$, dependendo do tipo de edificação (SACKS E BARAK, 2008).

O presente trabalho é baseado na utilização de duas ferramentas de modelagem:

- Rhinoceros - software de modelagem tridimensional que permite a criação de curvas NURBS (Non Uniform Rational Basis Spline).

- Grasshopper - Plugin para Rhinoceros que permite trabalhar no Rhinoceros a partir de parâmetros. O Grasshopper possui uma interface gráfica que permite visualizar e manipular os dados de forma mais intuitiva.

\subsection{Fabricação Digital}

As Tecnologias de Informação e Comunicação (TIC) têm proporcionado diversas mudanças nas relações humanas. A popularização da internet a partir da década de 1990 iniciou uma revolução em vários setores industriais, notadamente as empresas de mídia - música e cinema, principalmente - que observaram a derrocada de seus modelos de negócios e a emergência de novos modelos que substituíram produtos (CDs, Fitas) por serviços (distribuição digital, streaming).

Ao mesmo tempo, com a facilidade de acesso que o novo modelo oferecia, a segmentação do mercado foi estendida a níveis inéditos, contrariando o Princípio de Pareto. O Princípio de Pareto, também conhecido como regra $80-20$, aponta que $80 \%$ das consequências são geradas por $20 \%$ das causas. Aplicado ao mercado, o princípio indica que $20 \%$ dos produtos são responsáveis por $80 \%$ das vendas.

Este fenômeno, chamado de Cauda Longa por Chris Anderson (2006), apresenta a transição do mercado de massa para o mercado de nicho. Esta transição, mais evidente no mercado de produtos digitais, como audiovisual, tem mostrado seus primeiros avanços no mercado de produtos físicos.

Equipamentos destinados à fabricação de produtos, antes restritos aos parques fabris (devido ao custo ou espaço necessário para sua acomodação e funcionamento), atualmente 


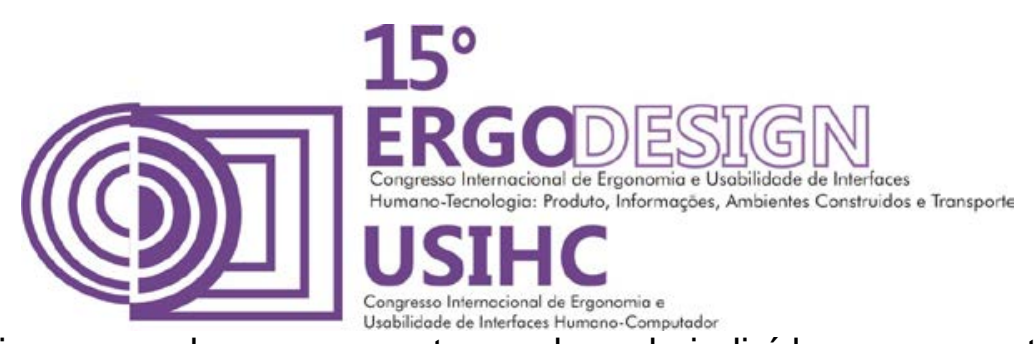

estão disponíveis para qualquer pessoa, tornando cada indivíduo em um potencial projetista e/ou fabricante. Máquinas como impressoras e digitalizadores tridimensionais, máquinas de corte e fresadoras, são ofertadas no varejo em versões compactas e de custo relativamente baixo em relação aos equipamentos industriais. Estas máquinas, associadas a um computador com software CAD, podem transformar um escritório em uma pequena unidade fabril (ANDERSON, 2012).

Conforme Neil Gershenfeld (2012), o termo "fabricação digital" geralmente se refere ao processo de produção controlado por computador, que remete à primeira fresadora controlada numericamente (CNC - Computer Numeric Control), desenvolvida pelo MIT em 1952. Porém, Gershenfeld afirma que o termo abriga um significado mais específico: o processo de manufatura onde os materiais empregados são, também, digitais. O mesmo autor ainda afirma que "a fabricação digital permitirá às pessoas projetarem e produzirem objetos materiais sob demanda, onde e quando forem necessários" (GERSHENFELD, 2012, p. 43).

\subsection{Modelagem e prototipagem}

A modelagem e a parametrização do produto foram realizadas através do software Rhinoceros 3D com o plugin Grasshopper. Após esta fase, foram realizados protótipos para teste do conceito com a máquina de corte laser Yueming CMA-1200.

\subsubsection{Grasshoper}

Grasshopper é um plugin do software de modelagem tridimensional Rhinoceros. O Grasshopper adiciona ao Rhinoceros a funcionalidade de modelagem paramétrica para objetos tridimensionais. O plugin funciona através de um algoritmo que executa uma sequência de comandos tridimensionais do Rhinoceros. O algoritmo, também chamado de circuito, é montado através uma linguagem de programação visual, no qual cada componente representa um comando já existente no Rhinoceros.

O fluxo de execução dos comandos ocorre a partir de conexões que podem ser estabelecidas entre os componentes disponíveis. Os resultados são visualizados em tempo real no próprio Rhinoceros.

Alguns componentes, como os sliders, permitem a inserção de dados podendo ser configurados para receber um número qualquer, real ou inteiro, dentro de um intervalo definido. Estes componentes atuam na parametrização do modelo, fornecendo valores como largura, espessura e distância entre objetos, entre outros. No momento em que um determinado valor é alterado, todo o modelo é reconstruído de acordo com o novo valor inserido nos campos de dados.

No início do desenvolvimento, apenas o Grasshopper foi utilizado na modelagem do produto. Após várias tentativas, o nível de complexidade do circuito para a execução tarefas relativamente simples, como desenhar perfis em duas dimensões, exigiu o uso de ferramentas complementares para a realização da tarefa. Desta forma, o próprio Rhinoceros foi utilizado para modelar os perfis em duas dimensões e, a partir de um perfil pré definido, foi criado o algoritmo para a parametrização.

Como o conceito do produto apresenta dobras, adotou-se uma simplificação em sua modelagem paramétrica, uma vez que devia-se criar projeções para resolver as dobras, e logo após desfazer as projeções, pois o protótipo seria construído através de chapas planas. Determinadas medidas foram escolhidas como entradas de valores para a parametrização da modelagem. O Quadro 1 apresenta detalhadamente os parâmetros utilizados no circuito. 


\section{(CD)] $15^{\circ}$ URGODESIGN}

Quadro 1: Parâmetros utilizados no circuito

\begin{tabular}{|l|l|}
\hline Largura & $\begin{array}{l}\text { Define a largura do perfil e a largura da célula de } \\
\text { repetição. }\end{array}$ \\
\hline Altura & Define a altura do perfil e a altura da célula de repetição. \\
\hline Quantidade $\mathbf{X}$ & Define a quantidade de repetições no sentido do eixo X. \\
\hline Quantidade Y & Define a quantidade de repetições no sentido do eixo y. \\
\hline Borda & \begin{tabular}{l} 
Define a largura da borda adicionada ao total da largura. \\
\hline Ângulo
\end{tabular} \\
\hline
\end{tabular}

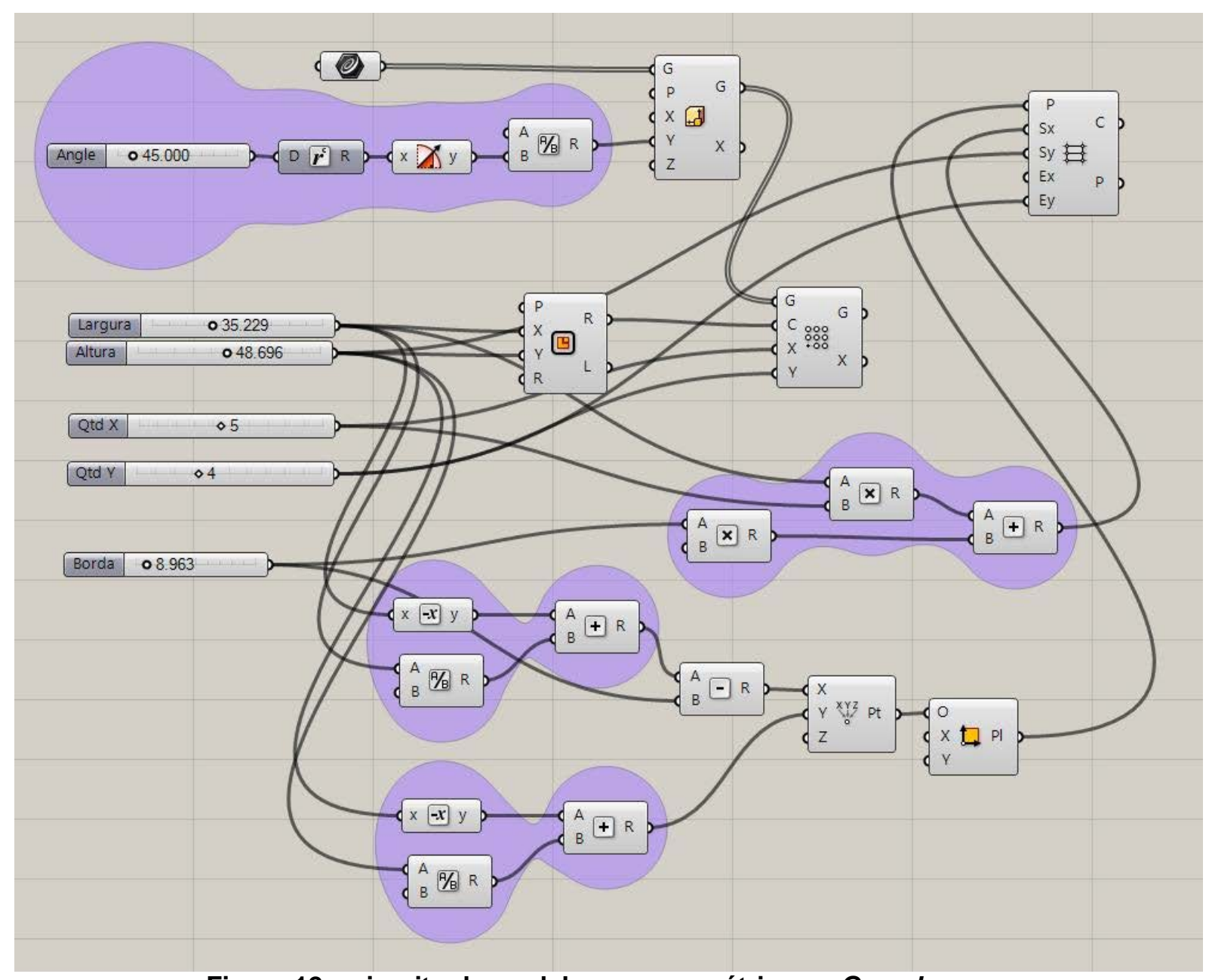

Figura 12 - circuito de modelagem paramétrica no Grasshopper.

Elaborado pelos autores, com base na pesquisa realizada. 


\subsubsection{Modelos}

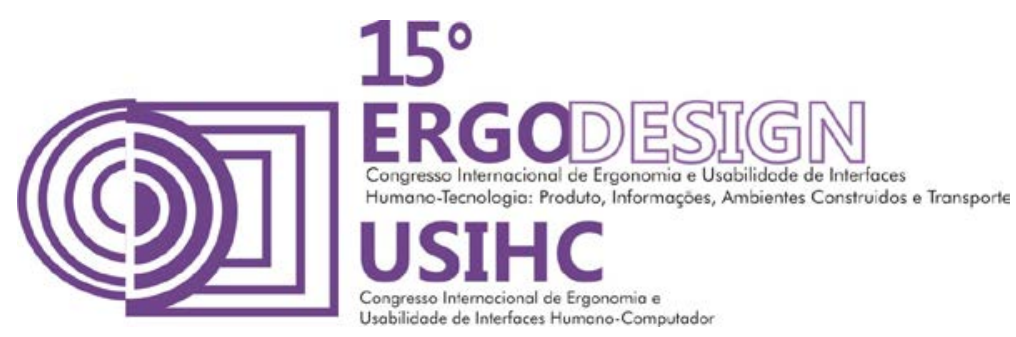

Após a modelagem e parametrização do produto, foram realizados protótipos para teste do conceito do produto. Para a realização da prototipagem foi utilizado a máquina de corte laser Yueming CMA-1200 do laboratório Virtual Design da UFRGS. Como o principal conceito escolhido para o desenvolvimento do produto é a flexibilidade, o corte laser mostrou-se eficiente para a prototipagem a partir de chapas dobráveis.

Para atingir o objetivo proposto de dobra nas chapas, testes foram realizados para se determinar a força e profundidade do corte, de tal maneira que o corte não atravessasse o material, mas sim apenas o marcasse, diminuindo sua espessura. Desta forma, facilitando a dobra da mesma.

As primeiras versões prototipadas, ficaram muito frágeis, quebrando nas dobras durante a montagem do produto (Figura 13). A partir da parametrização, as medidas foram aumentadas de forma a aumentar a resistência do produto (Figuras 14 e 15).

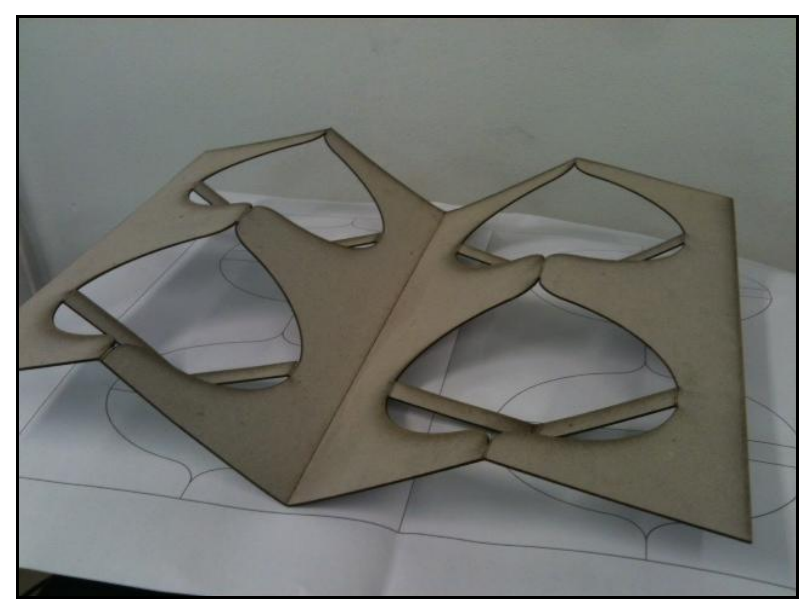

Figura 13 - primeiro protótipo produzido.

Elaborado pelos autores, com base na pesquisa realizada.

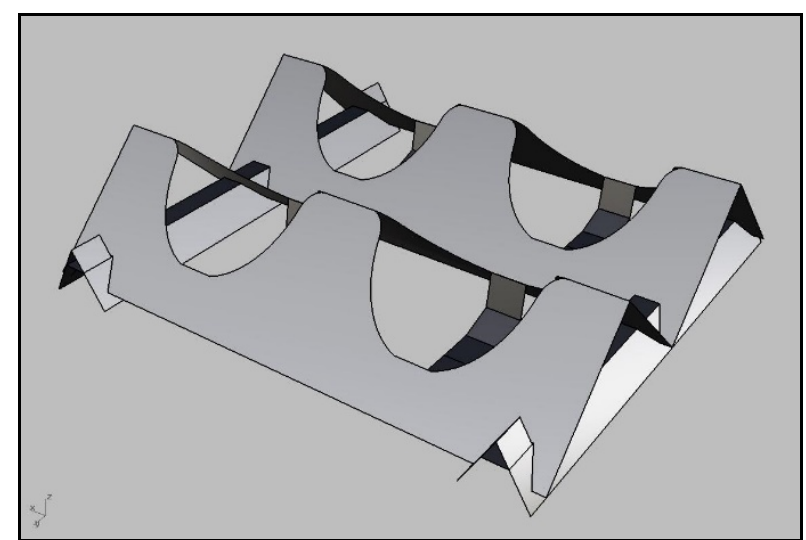

Figura 14 - modelo virtual com reforços estruturais.

Elaborado pelos autores, com base na pesquisa realizada. 


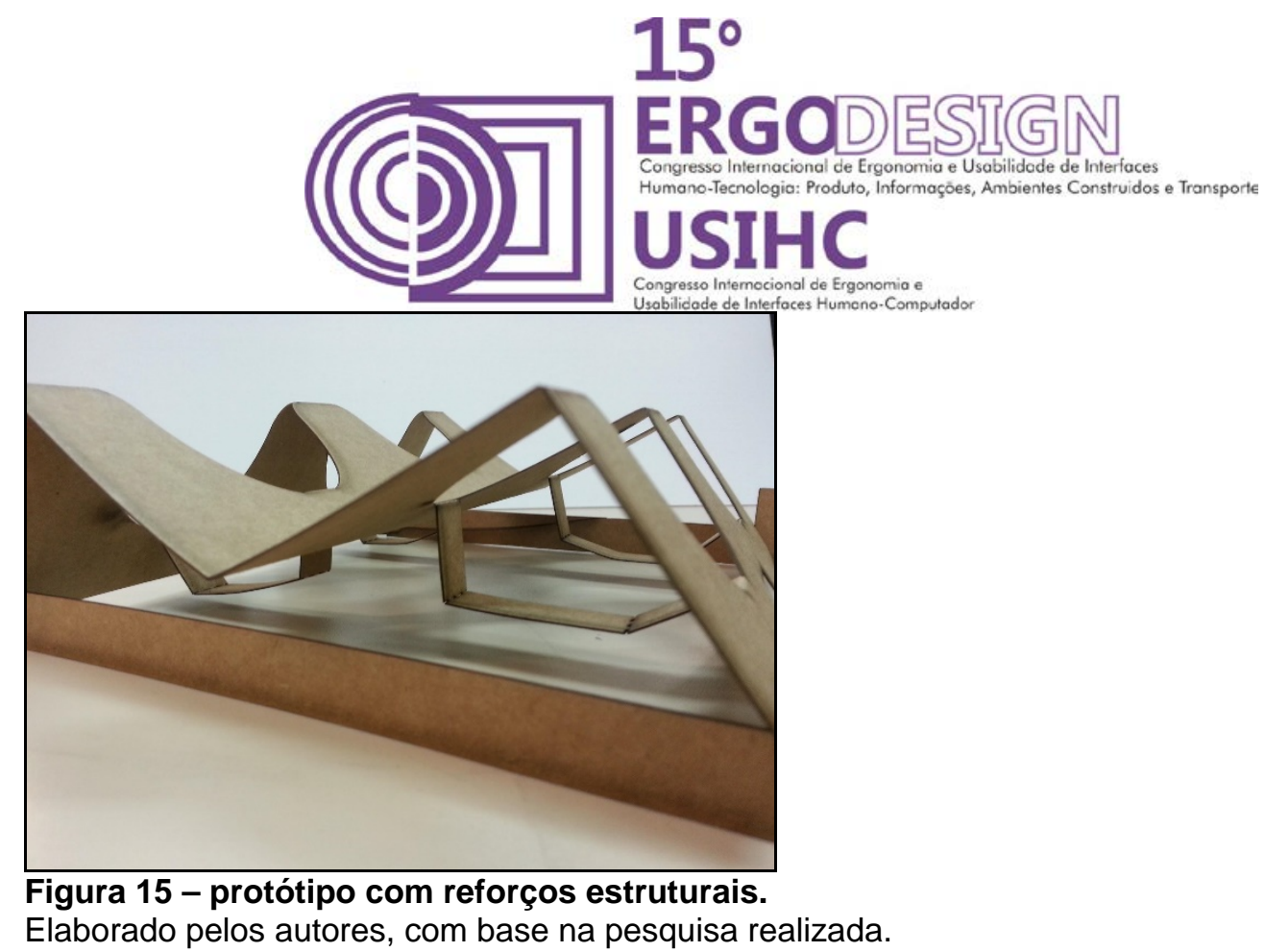

\section{DISCUSSÃO}

A fabricação digital possibilita a qualquer indivíduo, fabricar e manufaturar seus próprios protótipos e produtos em qualquer lugar (autor). Isto torna-se uma oportunidade para qualquer mercado, incluindo o nicho escolhido para a realização deste trabalho, as pequenas feiras. As embalagens das pequenas feiras são normalmente artesanais e de baixa qualidade. Uma nova embalagem de fácil manuseio, que atendesse corretamente a todas as funcionalidades e com apelo estético, incrementando a gôndola de qualquer vendedor da feira.

O protótipo gerado neste trabalho utilizou um material similar ao papelão ondulado, que segundo fulano é o material mais adequado para cumprir com os requisitos de projeto de embalagem. Dessa forma, no caso de produção do produto, seria necessária quase nenhuma adaptação do protótipo ao produto final.

O designer deve prever quais parâmetros deverão ser influenciados pela parametrização e quais não devem ser. Entretanto, deve-se atentar a natureza imprevisível do processo de design (BARRIOS HERNANDEZ, 2006, p. 310). Isso corrobora com o que aconteceu neste trabalho, pois a modelagem com o Grasshopper tornou-se insustentável, necessitando começar a modelagem do protótipo a partir de uma modelo prévio no Rhinoceros.

Foram realizados diversos testes com o protótipo, seguidos de ajustes no projeto, até conseguir atingir a flexibilidade desejada para o produto. Isso demonstra que por mais que existam ferramentas que podem simular efeitos de materiais, o papel do protótipo físico no teste é fundamental para o processo de projeto.

\section{CONCLUSÃO}

O software Grasshopper mostra-se uma ferramenta eficaz para o desenvolvimento de produtos a partir de um determinado conceito. A parametrização é um novo paradigma que torna o processo de concepção do produto mais flexível. Com a facilidade de ajustar os parâmetros em tempo real, ganha-se não só no tempo por evitar o retrabalho de modelagem, como ganha-se também a possibilidade de experimentar novas possibilidades de produtos com um mesmo conceito. 


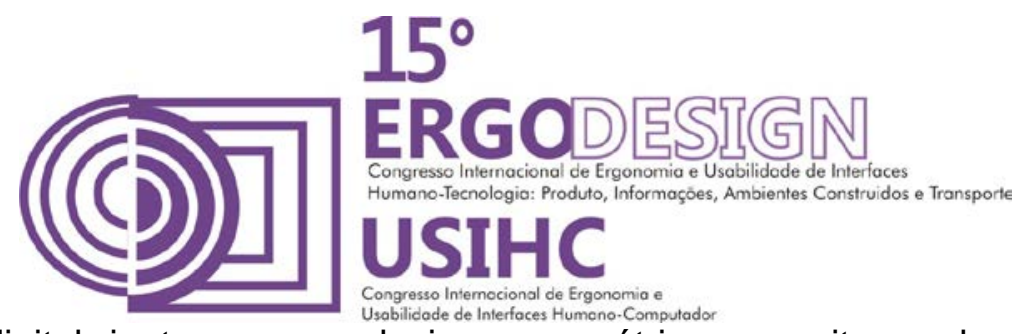

A fabricação digital junto com o design paramétrico, permite o desenvolvimento de protótipos de forma rápida e eficiente. Ajustando poucos parâmetros foi possível produzir um novo protótipo. Dessa forma, pode-se testar os protótipos e ajustar os requisitos necessários para se atingir o produto final desejado.

\section{REFERÊNCIAS BIBLIOGRÁFICAS}

ABRE - Associação Brasileira de Embalagem. Embalagem. 2014. Disponível em: $<$ http://www.abre.org.br/setor/apresentacao-do-setor/a-embalagem/>.

ANDERSON, Chris. A Cauda Longa: do mercado de massa para o mercado de nicho. Rio de Janeiro: Elsevier, 2006.

ANDERSON, Chris. Makers: The New Industrial Revolution. New York: Random House LLC, 2012.

BARRIOS HERNANDEZ, C. R. Thinking parametric design: introducing parametric Gaudi. Design Studies, v. 27, n. 3, p. 309-324, 2006.

BORDIN, M. R. Embalagens para frutas. In: SILVA, J. A. A.; DONADIO, L. C. (Eds.). Pós-colheita de citros. Jaboticabal: Funep, 2000. p. 33-43. (Boletim Citrícola, 13). Disponível em: $<\mathrm{http}: / / w w w . e s t a c a o e x p e r i m e n t a l . c o m . b r / d o c u m e n t o s / B C \_13 . p d f>$.

CALBO, Adonai Gimenez; LUENGO, Rita de Fátima Alves. Embalagens para comercialização de hortaliças e frutas. Circular Técnica 44. 2006: EMBRAPA, Brasília.

CARDOZO, Gissele Azevedo. Proposta de Jogo para a Solução de Problemas Não Estruturados com a Utilização de Técnicas Criativas. 104 f. Dissertação de Mestrado - Universidade Federal do Rio Grande do Sul. 2012.

GERSHENFELD, Neil. How to Make Almost Anything: The Digital Fabrication Revolution. Foreign Affairs, v. 91, p. 43, 2012.

GROSS, M. D. Relational modeling: A basis for computer-assisted design. In: MCCULLOUGH, M.; MITCHELL, W. J.; PURCELL, P. A. (ORGS.) The Electronic design studio: knowledge and media in the computer era. Cambridge: MIT Press, 1990.

HORTIBRASIL. Perguntas e Respostas sobre Embalagens de Produtos Hortifrutícolas. 2009. Disponível em: <http://www.hortibrasil.org.br/jnw/images/stories/biblioteca/faqemb/faq.htm>.

KHABAZI, Zubin. Generative Algorithms (using Grasshopper). 2012 : Morphogenesism.

MONEDERO, Javier. Parametric design: a review and some experiences. Automation in Construction, v. 9, n. 4, p. 369-377, 2000.

PAYNE, Andrew; ISSA, Rajaa. Manual de Grasshopper, Segunda Edición. 2009 : LIFT architects. Disponível em: <http://www.grasshopper3d.com/page/tutorials-1>. Acesso em: 30 jan. 2014.

ONU BR. Desperdício global de alimentos gera prejuízo de $\mathbf{7 5 0}$ bilhões de dólares por ano, calcula FAO. Nações Unidas no Brasil. 2013. Disponível em: <http://www.onu.org.br/desperdicioglobal-de-alimentos-gera-prejuizo-de-750-bilhoes-de-dolares-por-ano-calcula-fao/>. Acesso em: 30 jan. 2014.

SACKS, R.; BARAK, R. Impact of three-dimensional parametric modeling of buildings on productivity in structural engineering practice. Automation in Construction, v. 17, n. 4, p. 439-449, 2008. 